\title{
Value of PI of uterine artery at 23-24 weeks in the prediction of adverse pregnancy outcome
}

\author{
Anshu Dhar*, Indu Kaul
}

Department of Obstetrics and Gynecology, Government Medical College, Jammu, J and K, India

Received: 22 September 2017

Accepted: 27 October 2017

\section{*Correspondence:}

Dr. Anshu Dhar,

E-mail: ansdhar@gmail.com

Copyright: (C) the author(s), publisher and licensee Medip Academy. This is an open-access article distributed under the terms of the Creative Commons Attribution Non-Commercial License, which permits unrestricted non-commercial use, distribution, and reproduction in any medium, provided the original work is properly cited.

\begin{abstract}
Background: Increased resistance in uteroplacental circulation is associated with pregnancy complications. The aim of this study was to determine the role of uterine artery PI at 23-24 weeks gestation in predicting adverse pregnancy outcomes.

Methods: 200 singleton pregnancies were prospectively examined with color Doppler to determine the PI of uterine artery at 23-24 weeks and study its correlation with subsequent development of adverse maternal and fetal outcomes defined as any or the combination of preeclampsia, intrauterine growth restriction (IUGR), intrauterine death (IUD), preterm delivery and placental abruption.

Results: There were 13 cases (6.5\%) with abnormal uterine artery Doppler results and $8(61.5 \%)$ of them developed preeclampsia, out of these 8,1 had IUGR as well and 3 had iatrogenic preterm delivery due to severe preeclampsia. 2 $(15.4 \%)$ out of 13 had only IUGR. The pregnancies with adverse outcomes had significantly higher mean PI than those with normal outcomes $(1.2 \pm 0.3$ versus $0.857 \pm 0.179 ; \mathrm{p}<0.001)$. The sensitivity, specificity, PPV and NPV of PI $\geq 95^{\text {th }}$ percentile in the prediction of adverse pregnancy outcome was $35.71 \%, 98.26 \%, 76.92 \%$ and $90.37 \%$ respectively. The birth weight in higher mean PI group was significantly lower than in pregnancies with PI $<95^{\text {th }}$ percentile $(2.33 \pm 0.49 \mathrm{~kg}$ versus $2.86 \pm 0.48 \mathrm{~kg}$; $\mathrm{p}<001)$. No cases of spontaneous preterm labor, IUD or abruption were present in higher mean PI group.

Conclusions: Increased uterine artery PI at 23-24 weeks of pregnancy is associated with an increased risk of adverse pregnancy outcomes.
\end{abstract}

Keywords: IUGR, Preeclampsia, Pulsatility index, Uterine artery

\section{INTRODUCTION}

Impaired placentation is one of the major causes of perinatal mortality and morbidity and has been associated with preeclampsia, IUGR, IUD and abruptio placenta. Impaired placentation results from failure or inadequate trophoblastic invasion of the spiral arteries, resulting in increased impedance of flow in the uterine arteries. ${ }^{1}$ The failure to get a low resistance circulation is associated with a subsequent risk of adverse pregnancy outcome. ${ }^{2}$ It is possible to assess the impedance in uteroplacental circulation by means of uterine artery Doppler. ${ }^{3}$ Its importance lies in the fact that the changes in uterine artery Doppler can be detected long before the onset of aforementioned complications making it possible to be used as a screening tool. These findings have been supported by histological studies that show that Doppler resistance index is inversely related to the percentage of vessels with trophoblastic invasion. ${ }^{4}$ Predicting the risk of these complications may improve the outcome by providing appropriate antenatal surveillance and therapeutic intervention. 
Extensive research carried out in the past two decades has shown the role of uterine artery Doppler in screening for adverse pregnancy outcomes in the first and second trimester of pregnancy with different sensitivities and specificities. $^{5-8}$

The aim of this study was to determine the sensitivity, specificity, positive and negative predictive value of the uterine artery PI at 23-24 weeks in the prediction of adverse pregnancy outcome in our study population.

\section{METHODS}

The prospective study was carried out in 200 singleton pregnancies attending the OPD of SMGS Hospital, Government Medical College, Jammu for prenatal care at 23-24 weeks. Written informed consent was obtained from all the participants. Singleton pregnancies with absence of fetal malformation, no history of smoking, alcoholism, drug abuse, diabetes mellitus or hypothyroidism were included in the study. Maternal age, parity and history of medical disease were recorded. Gestational age determination was based on a best estimate from menstrual history, clinical gestational age or fetal biometry preferably in the first trimester or early second trimester.

Uterine artery Doppler examinations were performed by trained faculties using Toshiba Xario whole body color Doppler and Kantron whole body color Doppler machine. The patient was placed in semi recumbent position. A small amount of ultrasound coupling gel was applied on the transducer and images and Doppler mapping were acquired, keeping the angle of insonation less than $30^{\circ}$.

The uterine artery was identified at the point of its apparent crossing over the external iliac artery. After image acquisition, the Doppler velocimetric measurements of maternal uterine artery were performed. Pulsed wave Doppler was then used to obtain three consecutive waveforms. Pulsatility index of each uterine artery - right and left was measured, and the mean of both sides was calculated. This mean PI was considered in the study. In this study we have used reference ranges stated by Gomez et al for PI. ${ }^{9}$

PI was considered abnormal when its value was $\geq 95^{\text {th }}$ percentile for gestational age. All the patients with a value of pulsatility index $\geq 95^{\text {th }}$ percentile for gestational age were included in Group $\mathrm{A}$ and those with values below $95^{\text {th }}$ percentile was included in Group B. The sensitivity, specificity, positive and negative predictive values for a cut-off of a mean PI $\geq 95^{\text {th }}$ percentile for gestational age in prediction of adverse pregnancy outcomes were calculated.

The measures of outcome were development of preeclampsia, IUGR, preterm delivery, placental abruption and fetal death. Preeclampsia was defined according to the guidelines of the International Society for the Study of Hypertension in Pregnancy as blood pressure at least $140 / 90 \mathrm{mmHg}$ on two occasions, 4 hours apart, with $300 \mathrm{mg}$ or more proteinuria during 24 hours after 20 weeks gestation. ${ }^{10}$ IUGR was diagnosed if the estimated fetal weight was below the $10^{\text {th }}$ percentile for gestational, together with a Doppler PI in the umbilical artery above the $95^{\text {th }}$ percentile, or if the estimated fetal weight was below the $3^{\text {rd }}$ percentile irrespective of the umbilical artery Doppler. ${ }^{11}$ Preterm delivery was defined as delivery before 37 weeks of gestation. All pregnant women received routine antenatal care and were followed up till delivery. Statistical analysis was performed using SPSS version 21.

\section{RESULTS}

A cohort of 200 singleton pregnancies subjected to uterine artery Doppler examination at 23-24 weeks, was included in the study population. The mean age of our study population was $26 \pm 3.1$ years with maximum number of cases $102(51 \%)$ in the age group of 20-25 years. Majority of cases $107(53.5 \%)$ were nulliparous while $74(37 \%)$ and $19(9.5 \%)$ had parity 1 and 2 respectively.

Of the total 200 patients, $13(6.5 \%)$ had PI $\geq 95^{\text {th }}$ percentile for that gestational age (group A) while the rest i.e.187 $(93.5 \%)$ had PI below $95^{\text {th }}$ percentile (group B) for that gestational age. Mean PI of group A was $1.472 \pm .059$. Mean PI of group B was $0.862 \pm 0.186$.

Table 1 shows comparison of mean PI in pregnancies with normal and adverse outcomes. Mean PI in patients with no adverse outcome was significantly lower than mean PI of pregnancies with adverse outcome.

Table I: Comparison of mean PI in pregnancies with normal and adverse outcome.

\begin{tabular}{|ll|}
\hline Outcome & PI $($ Mean \pm SD $)$ \\
\hline Uneventful & $0.857 \pm 0.179$ \\
\hline Adverse outcome & $1.2 \pm 0.3$. \\
\hline p & $<0.001$ \\
\hline
\end{tabular}

Table 2: Distribution of patients according to outcome of present pregnancy.

\begin{tabular}{|llll|}
\hline Outcome & Group A & Group B & Total \\
& No. $(\%)$ & No. $(\%)$ & No. $(\%)$ \\
\hline Adverse & $10(76.9)$ & $18(9.6)$ & $28(14)$ \\
\hline 28-34 weeks* & $8(61.5)$ & $4(2.1)$ & $12(6)$ \\
\hline$>34$ weeks* & $2(15.4)$ & $14(7.5)$ & $16(8)$ \\
\hline Uneventful & $3(23.1)$ & $169(90.4)$ & $172(86)$ \\
\hline Total & 13 & 187 & 200 \\
\hline
\end{tabular}

*Out of 8 patients who developed an adverse pregnancy outcome before 34 weeks, 5 patients developed early preeclampsia, 2 patients had IUGR and 1 patient had preeclampsia along with IUGR. 2 patients in group A developed preeclampsia after 34 weeks. 
Table 2 and 3 show the pregnancy outcome in the two groups $\mathrm{A}$ and $\mathrm{B}$.

Table 3: Distribution of population according to the type of complication developing during follow up.

\begin{tabular}{|llll|}
\hline Adverse outcome & $\begin{array}{l}\text { Group A } \\
\text { No. }(\%)\end{array}$ & $\begin{array}{l}\text { Group B } \\
\text { No. }(\%)\end{array}$ & $\begin{array}{l}\text { Total } \\
\text { No. }(\%)\end{array}$ \\
\hline Pre-eclampsia & $8(61.5)$ & $4(2.1)$ & $12(6)$ \\
\hline Early ( $\leq 34$ weeks) & $6(46.1)$ & $0(0)$ & $6(3)$ \\
\hline Late (>34 weeks) & $2(15.4)$ & $4(2.1)$ & $6(3)$ \\
\hline Gestational HTN & 0 & $5(2.7)$ & $5(2.5)$ \\
\hline $\begin{array}{l}\text { Preterm birth } \\
\text { (total) }\end{array}$ & $3(23.1)$ & $6(3.2)$ & $9(4.5)$ \\
\hline Spontaneous & 0 & $5(2.7)$ & $5(2.5)$ \\
\hline Iatrogenic & $3(23.1)$ & $1(0.5)$ & $4(2)$ \\
\hline Abruption & 0 & $2(1.1)$ & $2(1)$ \\
\hline IUGR & $3(23.1)$ & $3(1.6)$ & $6(3)$ \\
\hline Combined* & $4(30.8)$ & $2(1.1)$ & $6(3)$ \\
\hline
\end{tabular}

*4 patients in Group A had more than 1 adverse outcome. 3 had preeclampsia + preterm delivery (iatrogenic). 1 had IUGR + preeclampsia. 2 patients in Group B had combined adverse outcome (IUGR+ abruption and preterm birth + preeclampsia).

Out of the 18 patients in group B who developed an adverse pregnancy outcome, only 4 patients developed complications before 34 weeks in the form of preterm labour. Rest of the complications in group B were detected after 34 weeks.

No cases of abruption, IUD, gestational hypertension or spontaneous preterm birth were noted in group A. However, there were 3 cases of iatrogenic preterm birth due to severe preeclampsia in group A.

Table 4: Comparison of birth weights in Group A and B.

\begin{tabular}{|ll|}
\hline Group & Birth weight $($ Mean \pm SD) \\
\hline A & $2.33 \pm 0.49 \mathrm{~kg}$ \\
\hline B & $2.86 \pm 0.48 \mathrm{~kg}$ \\
\hline p value & $<.001$ \\
\hline
\end{tabular}

Table 3 shows comparison of birth weights in normal and abnormal Doppler group. Clearly the birth weight in group with higher PI is significantly less than in group with lower PI.

Table 5 presents the screening characteristics of a mean PI $\geq 95^{\text {th }}$ percentile for predicting adverse pregnancy outcome.

Table 5: The screening characteristics of a mean uterine artery $\mathrm{PI} \geq 95^{\text {th }}$ percentile.

\begin{tabular}{|lllll|}
\hline Outcome & Sensitivity (\%) & Specificity (\%) & PPV (\%) & NPV (\%) \\
\hline Preeclampsia & $66.66 \%$ & $97.34 \%$ & $61.54 \%$ & $97.86 \%$ \\
\hline IUGR & $50 \%$, & $94.84 \%$ & $23.07 \%$ & $98.39 \%$ \\
\hline Preterm delivery* & $33.33 \%$ & $94.76 \%$ & $23.07 \%$ & $96.79 \%$ \\
\hline Overall combined & $35.71 \%$ & $98.26 \%$ & $76.92 \%$ & $90.37 \%$ \\
\hline
\end{tabular}

*There were no cases of spontaneous preterm birth in abnormal Doppler group. The values calculated above are for iatrogenic preterm delivery.

Increased PI in the present study had a sensitivity of $100 \%$, specificity of $96.39 \%$, PPV of $46.15 \%$ and NPV of $100 \%$ for the detection of early onset preeclampsia developing before 34 weeks of gestation.

\section{DISCUSSION}

In a normal pregnancy, resistance of uteroplacental circulation decreases significantly with advancing gestational age as the extravillous trophoblast invades the maternal spiral vessels replacing the endothelial and muscular layers and converting the spiral arteries from narrow muscular vessels to wide non-muscular channels independent of maternal vasomotor control, that can accommodate the increased uteroplacental blood flow of pregnancy. In the absence of this physiologic decrease, a higher incidence of hypertensive disorders and adverse perinatal outcomes could be expected. This is reflected in increased PI which can thus be used to predict the development of adverse pregnancy outcomes associated with impaired trophoblastic invasion. The calculated, specificity, positive and negative predictive value of PI $\geq 95^{\text {th }}$ percentile in the prediction of adverse pregnancy outcome in our study was $35.71 \%, 98.26 \%, 76.92 \%$ and $90.37 \%$ There was a statistically significant relationship between the PI and the risk of adverse pregnancy outcome $(\mathrm{p}<0.001)$.

The association between adverse pregnancy outcome and the higher uterine artery mean PI in this study is in agreement with other uterine artery Doppler studies in the second trimester., 7,12,13 Mean of PI in patients with adverse pregnancy outcome was $1.2 \pm 0.3$. that was significantly higher as compared to those with no adverse outcome $(0.857 \pm 0.179)$. The sensitivity of abnormal uterine artery Doppler for all adverse outcomes was $35.71 \%$ which is compatible with ranges from $20-60 \%$ of older studies. ${ }^{12-14} 8(61.5 \%)$ patients in group A out of 13 developed an adverse pregnancy outcome between 28-34 weeks of gestation while in $2(15.4 \%)$ it was detected 
after 34 weeks (the outcome after 34 weeks was late preeclampsia). In group B, $4(2.1 \%)$ patients developed an adverse outcome before 34 weeks in the form of preterm labor, while in the rest the complications developed after 34 weeks. This is in agreement with the fact that complications occurring due to impaired trophoblastic invasion would tend to manifest earlier than those outcomes whose etiology is unrelated to abnormal placentation

PI $\geq 95^{\text {th }}$ percentile had a sensitivity of $66.66 \%$, specificity of $97.34 \%$, PPV of $61.54 \%$ and NPV of $97.86 \%$ for preeclampsia. The sensitivity was similar to $62 \%$ obtained by Kurdi et al. ${ }^{15}$

It is noteworthy that increased PI in the present study had a sensitivity of $100 \%$, specificity of $96.39 \%$ PPV of $46.15 \%$ and NPV of $100 \%$ for the detection of early onset preeclampsia developing before 34 weeks of gestation. This has also been demonstrated in previous studies where uterine Doppler screening was better in predicting severe early-onset disease or PE associated with IUGR, with sensitivities of 80 to $90 \%$ suggesting that there is a subgroup of late onset cases with minimum placental involvement. ${ }^{16}$ The classification of PE into early and late onset has clinical importance since early-onset $\mathrm{PE}$ is commonly associated with IUGR, abnormal uterine Doppler, and adverse maternal and neonatal outcomes. ${ }^{17-20}$

In contrast, late-onset PE is mainly associated with a milder form of maternal illness with low rate of fetal involvement, so perinatal outcome is usually favorable. ${ }^{17,19}$

Patients with $\mathrm{PI} \geq 95^{\text {th }}$ percentile had a significantly lower birth weight $(2.33 \pm 0.49 \mathrm{~kg})$ compared to those with PI $<95^{\text {th }}$ percentile $(2.86 \pm 0.48 \mathrm{~kg})$. This finding was similar to that obtained by Ghi et al who found a statistically significant difference in the birth weights of normal and abnormal Doppler group in his study. ${ }^{21}$ In the present study $3(23.1 \%)$ patients in group A developed IUGR with PI having a sensitivity of $50 \%$ similar to that obtained by Ashraf $\mathrm{J}$ et al. ${ }^{22}$ The specificity, PPV and NPV were $94.84 \%, 23.07 \%$ and $98.39 \%$ respectively. Similar values have been obtained in some of the previous studies. ${ }^{22-24}$ There was no association between uterine artery PI $>95^{\text {th }}$ percentile and spontaneous preterm delivery in the present study. Similar results have been obtained in previous study. ${ }^{22}$ However the result of the study by Fonseca et al showed higher resistance in women with preterm delivery before 33 weeks. ${ }^{25}$ There were no cases of IUD in the present study. Only two subjects had abruption but those did not have an abnormal value of PI.

\section{CONCLUSION}

The importance of uterine artery Doppler as a screening tool lies in its high NPV and specificity for adverse pregnancy outcome which can allow for categorization of pregnant women into a low risk and high risk group so that women in the low risk group can be followed up routinely and the resources can be diverted towards high risk group to improve pregnancy outcome by increased surveillance and timely intervention.

\section{ACKNOWLEDGMENTS}

Authors thank the Department of Radiology, GMC Jammu for making this work possible.

Funding: No funding sources

Conflict of interest: None declared

Ethical approval: The study was approved by the Institutional Ethics Committee

\section{REFERENCES}

1. Khong TY, De Wolf F, Robertson WB, Brosens I. Inadequate maternal vascular response to placentation in pregnancies complicated by preeclampsia and by small-for gestational age infants. Br J Obstet Gynaecol. 1986;93:1049-59.

2. Valensise H, Bezzeccheri V, Rizzo G, Tranquilli AL, Garzetti GG, Romanini C. Doppler velocimetry of the uterine artery as a screening test for gestational hypertension. Ultrasound Obstet Gynecol. 1993;3:18-22.

3. Campbell S, Pearce JM, Hackett G, Cohen-Overbeek T, Hernandez C. Qualitative assessment of uteroplacental blood flow: Early screening test for high-risk pregnancies. Obstet Gynecol. 1986;68:64953.

4. Prefumo F, Sebire NJ, Thilaganathan B. Decreased endovascular trophoblast invasion in first trimester pregnancies with high-resistance uterine artery Doppler indices. Human Reprod. 2004;19(1):206-9.

5. Gomez O, Maritinez JM, Figueras F, del Río M, Borobio V, Puerto B, et al. Uterine artery Doppler at 11-14 weeks of gestation to screen for hypertensive disorders and associated complications in an unselected population. Ultrasound Obstet Gynecol. 2005;26:490-4

6. Campbell S. First-trimester screening for preeclampsia. Ultrasound Obstet Gynecol. 2005;26:4879.

7. Albaiges G, Missfelder-Lobos H, Lees C, Parra M, Nicolaides KH. One-stage screening for pregnancy complications by color Doppler assessment of the uterine arteries at 23 weeks' gestation. Obstet Gynecol. 2000;96:559-64.

8. North RA, Ferrier C, Long D, Townend K, KincaidSmith P. Uterine artery Doppler flow velocity waveforms in the second trimester for the prediction of preeclampsia and fetal growth retardation. Obstet Gynecol. 1994;83:378-86.

9. Gómez O, Figueras F, Martínez JM, Del Rio M, Palacio M, Eixarch E, et al. Sequential changes in uterine artery blood flow pattern between the first 
and second trimesters of gestation in relation to pregnancy outcome. Ultrasound Obstet Gynecol. 2006;28:802-8.

10. Brown MA, Lindheimer MD, de Swiet M, Van Assche A, Moutquin JM. The classification and diagnosis of the hypertensive disorders of pregnancy: statement from the International Society for the Study of Hypertension in Pregnancy (ISSHP). Hypertens Pregnancy. 2001;20: IX-XIV.

11. Soothill PW, Bobrow CS, Holmes R. Small for gestational age is not a diagnosis. Ultrasound in Obstetrics and Gynecology. 1999;13(4):225-8.

12. Bower S, Schuchter K, Campbell S. Doppler ultrasound screening as part of routine antenatal scanning: prediction of pre-eclampsia and intrauterine growth retardation. Int $\mathbf{J}$ Obstet Gynaecol. 1993;100(11):989-94.

13. Harrington K, Cooper D, Lees C, Hecher K, Campbell S. Doppler ultrasound of the uterine arteries: the importance of bilateral notching in the prediction of pre-eclampsia, placental abruption or delivery of a small-for-gestational-age baby. Ultrasound in Obstetrics and Gynecology. 1996;7(3):182-8.

14. Bower S, Bewley S, Campbell S. Improved prediction of preeclampsia by two stage screening of uterine arteries using the early diastolic notch and color Doppler imaging. Obstet Gynecol. 1993;82:7883.

15. Kurdi W, Campbell S, Aquilina J, England P, Harrington K. The role of color Doppler imaging of the uterine arteries at 20 weeks' gestation in stratifying antenatal care. Ultrasound Obstet Gynecol. 1998;12:339-45.

16. Papageorghiou AT, Yu CK, Bindra R, Pandis G, Nicolaides KH. Multicenter screening for preeclampsia and fetal growth restriction by transvaginal uterine artery Doppler at 23 weeks of gestation. Ultrasound in Obstetrics and Gynecology. 2001;18(5):441-9.

17. Sibai B, Dekker G, Kupferminc M. Pre-eclampsia. The Lancet. 2005;365(9461):785-99.

18. Murphy DJ, Stirrat GM. Mortality and morbidity associated with early-onset preeclampsia. Hypertension in Pregnancy. 2000;19(2):221-31.
19. Crispi F, Domínguez C, Llurba E, Martín-Gallán P, Cabero L, Gratacós E. Placental angiogenic growth factors and uterine artery Doppler findings for characterization of different subsets in preeclampsia and in isolated intrauterine growth restriction. Am J Obstet Gynecol. 2006;195(1):201-7.

20. Ness RB, Sibai BM. Shared and disparate components of the pathophysiologies of fetal growth restriction and preeclampsia. Am J Obstet Gynecol. 2006;195(1):40-9.

21. Ghi T, Youssef A, Piva M, Contro E, Segata M, Guasina F, et al. The prognostic role of uterine artery Doppler studies in patients with late-onset preeclampsia. Am J Obstet Gynecol. 2009;201(1):36-e1.

22. Ashraf J, Fatemeh A, Homeira V, Marsoosi V, Eslamian L. Multicenter screening for adverse pregnancy outcomes by uterine artery Doppler in the second and third trimester of pregnancy. Med Ultrason. 2013;15(2):95-100.

23. Barati M, Shahbazian N, Ahmadi L, Masihi S. Diagnostic evaluation of uterine artery Doppler sonography for the prediction of adverse pregnancy outcomes. J Res Med Sci. 2014;19(6):515-9.

24. Llurba E, Carreras E, Gratacos E, Juan M, Astor J, Vives A, et al. Maternal history and uterine artery Doppler in the assessment of risk for development of early and late onset pre-eclampsia and intrauterine growth retardation. Obstet Gynecol Int. 2009;2009:275613.

25. Fonseca E, Yu CK, Singh M, Papageorghiou AT, Nicolaides KH. Relationship between secondtrimester uterine artery Doppler and spontaneous early preterm delivery. Ultrasound Obstet Gynecol. 2006;27:301-5.

Cite this article as: Dhar A, Kaul I. Value of PI of uterine artery at 23-24 weeks in the prediction of adverse pregnancy outcome. Int J Reprod Contracept Obstet Gynecol 2017;6:5435-9 